\title{
O ENCONTRO DE PIAGET E VYGOTSKY NA CASA DE MORIN
}

Adriana Croti $^{1,2}$, Carmen Lúcia Dias ${ }^{2}$

${ }^{1}$ Faculdade Dom Bosco - FDB, Curso de Adm. Empresas, Cornélio Procópio, PR. ${ }^{2}$ Universidade do Oeste Paulista UNOESTE, Mestrado em Educação, Presidente Prudente, SP.E-mail: adrianacroti@hotmail.com

\section{RESUMO}

Minha formação acadêmica e práxis acontecem na Administração de Empresas, onde teorias foram construídas pelo impacto de forças sociais, políticas e econômicas das sociedades nas organizações. Essas forças, mescladas à tecnologia e inovação promovem o aparecimento de tendências de gestão, que se somam e são empregadas pelas organizações para enfrentar cenários. Foi com este olhar de mescla que cheguei ao Mestrado em Educação. Esta percepção, foi-se alterando com o conhecimento teórico e com a ideia de incompatibilidade entre Piaget e Vygotsy. Este artigo tem objetivo de criar um diálogo de ficção, embasado nas teorias de Jean Piaget, Lev Vygotksky e Edgar Morin, com a intenção de apresentar divergências e convergências dos pensamentos dos dois primeiros, e também, considerar, diante desta ficção uma suposta direção para a Educação sob o olhar de Morin. Este artigo fundamentou-se na própria teoria destes três autores e, na crítica de Vygotsky a Piaget e sua resposta.

Palavras chave: Piaget, Vygotsky, Morin, Desenvolvimento conhecimento.

\section{THE ENCOUNTER OF PIAGET AND VYGOTSKY AT MORIN'S HOUSE}

\begin{abstract}
My academic training and practice takes place in Business Administration, where theories were built by the impact of social, political and economic societies in organizations. These forces merged to technology innovation and promote the emergence of management trends, which add up and are used by organizations to face scenarios. It was with this look of mix I got to the Master of Education. This perception has been changing with the theoretical knowledge and the idea of incompatibility between Piaget and Vygotsy. This article has aimed to create a fictional dialogue, based on the theories of Jean Piaget, Lev Vygotksky and Edgar Morin, with the intention to present divergences and convergences of the first two thoughts, and also consider, on this fiction a supposed direction Education under the gaze of Morin. This article was based on the theory itself these three authors and the criticism of Piaget and Vygotsky to his answer.
\end{abstract}

Keywords: Piaget, Vygotsky, Morin, Cognitive development. 


\section{INTRODUÇÃO}

Minha formação acadêmica e práxis são na Administração de Empresas. No ambiente organizacional, os processos produtivos e os aspectos comportamentais conectados às constantes mudanças do ambiente externo dão ritmo à gestão. As teorias administrativas têm sua construção "com base no impacto das forças das sociedades nas organizações [...] forças sociais, políticas e econômicas." (DAFT, 2010, p. 42-43).

Essas forças mescladas à tecnologia e às teorias de gestão fazem com que as organizações busquem seu próprio aprimoramento como produtora de bens e serviços e, como fonte de capacitação das pessoas envolvidas neste processo para obter melhores resultados (SENGE, 2013). Assim, essas teorias e tendências são empregadas aos cenários enfrentados pelas organizações mundiais para continuar o ciclo de produção, de oferta de bens e serviços e de emprego.

Por isso, com um olhar de soma e mescla, a minha leitura desprovida dos paradigmas da Educação me fez ver, principalmente, as teorias de Piaget e Vygotsky como complementares. Contudo, esta percepção foi se desconstruindo a partir do meu aprofundamento teórico. Assim, pude observar que os aspectos definidos em cada teoria eram defendidos para o impasse, e que, no ambiente educacional acabou por tornar-se uma ortodoxia (DONGO-MONTOYA, 2013, p. 272).

Sendo assim, este artigo pretende criar um diálogo de ficção embasado nas teorias de Jean Piaget, Lev Vygotsky e Edgar Morin com a intenção de apresentar algumas divergências e convergências dos pensamentos dos dois primeiros e, também, considerar diante desta trama uma suposta direção para a Educação sob o olhar de Morin.

\section{O ENCONTRO}

Numa tarde, "participei" de uma reunião na casa de Edgar Morin com o objetivo de apreciar uma discussão entre Piaget, Vygotsky e o querido anfitrião sobre a construção do conhecimento e a educação. Na perspectiva deste encontro, e para melhor desfrutá-lo, busquei colocar em ordem os meus pensamentos e os conceitos teóricos ainda embaralhados.

Por isso, o primeiro ponto que considerei foi o conceito de escola. Logo, busquei respaldo em Gimeno Sacristán e Pérez Gómes (1998) que colocam que a educação cumpre o seu papel de socialização, contudo, apontam os autores, a necessidade da participação do homem na vida pública e o mundo do trabalho requer a intervenção da escola para atender e canalizar o processo de socialização. Complementando, (p. 15) colocam que cabe à escola provocar o desenvolvimento de "conhecimentos, ideias, atitudes e pautas de comportamento que permitam a incorporação eficaz no mundo civil, no âmbito da liberdade de consumo, da liberdade de escolha e participação política, da liberdade e responsabilidade na esfera da vida familiar."

Parti para o encontro tomando como base esta compreensão de educação e do ambiente escolar que aliadas às influências sociais, políticas, econômicas e tecnológicas impactam o mundo do trabalho e das organizações, ambos, meu universo de trabalho. Ansiava por esta conversa.

Edgar Morin me recebeu com um elegante sorriso, pouco tempo depois, chegou Jean Piaget e, logo em seguida, Vygotsky. Sentamos todos numa saleta confortável e agradável com uma luz morna que passava pelas cortinas.

Assim que Piaget chegou, apesar do turbilhão de sentimentos que me invadiu, pude recordar que sua ideia de pesquisa inicial era compreender como se constrói o conhecimento humano do mundo e do meio, onde o objeto deste conhecimento são os aspectos físicos, os culturais, os emocionais, as ideias, os pensamentos e os relacionamentos a partir da estruturação do vivido. E assim, essas condições se tornaram para ele o objeto do conhecimento (RAMOZZICHIAROTINO, 1988).

Piaget (1973a) iniciou a conversa dizendo que "a inteligência humana somente se desenvolve no indivíduo em função de interações sociais que são, em geral, demasiadamente negligenciadas." E continuou (1973b) 
Se tomarmos a noção do social nos diferentes sentidos do termo, isto é, englobando tanto as tendências hereditárias que nos levam à vida em comum e a imitação, como as relações 'exteriores' (no sentido de Durkheim) dos indivíduos entre eles, não se pode negar que, desde o nascimento, o desenvolvimento intelectual é, simultaneamente, obra da sociedade e do indivíduo. (PIAGET, 1973b, p.242).

Desta forma, ao me recordar das leituras de suas obras percebi que para Piaget esta condição torna-se muito ampla, assim, observa-se que para ele a questão individual como fonte de estudo torna-se mais evidente que a social. Sendo assim, Piaget entende que o homem epistemológico ${ }^{1}$ tem um desenvolvimento social diferente para as diversas faixas etárias e por isso sua individualidade se altera apresentando uma variação de qualidade e de capacidade de construção do conhecimento (RAMOZZI-CHIAROTINO, 1988).

Vygotsky ${ }^{2}$ rompeu o silêncio atento que mantinha e, colocou que seus estudos buscam compreender a maneira pela qual os indivíduos internalizam a linguagem no decorrer de seu desenvolvimento. Para ele, as formas superiores de comportamentos conscientes estavam nas relações sociais do homem com o meio. Contudo, "o homem não é apenas um produto de seu ambiente, é também um agente ativo no processo de criação deste meio" (VYGOTSKY, 2001, p. 25), ou seja, "a complexidade da estrutura humana deriva do processo de desenvolvimento profundamente enraizado nas relações entre história individual e social." (REGO, 1995, p. 26).

Nesta perspectiva, observa-se que para Piaget a construção da inteligência foi estudada pelas alterações internas, sem desconsiderar o social, enquanto que para Vygotsky tal construção ocorre da relação do exterior com o interior pela construção do pensamento e da linguagem. Por isso, Vygotsky ao estudar o comportamento humano como decorrência do social se dedicou "principalmente à construção de estudos que pudessem atestar a ideia de que o pensamento é culturalmente mediado, sendo que a linguagem é o meio principal desta mediação." (REGO, 1995, p. 31).

Com o início da conversa, olhei minhas anotações e notei um destaque assinalado "a fala egocêntrica emerge quando a criança transfere formas sociais e cooperativas de comportamento para a esfera das funções psíquicas interiores e pessoais." (VYGOTSKY, 1991, p. 17). Nota-se que este pensamento é compartilhado por Piaget, porém em caminho contrário. Neste momento, como observadora, mentalmente me questionei. E o que é o indivíduo? Respondi com meu pensar míope de "observadora de gente": uma construção de si como indivíduo influenciando e sendo influenciado pelo meio. Mas, e se eu tivesse nascido na China? De súbito, voltei minha atenção à conversa.

Piaget complementou que conhecer deve ter um sentido claro, e não é somente explicar nem tampouco somente viver. Conhecer é organizar, estruturar e explicar a partir do experienciado por meio do objeto do conhecimento, isto é, de sua ação cognitiva neste objeto, onde este pode ser pensamento, sentimento ou movimento (RAMOZZI-CHIAROTINO, 1988). E assim, dá ênfase à ideia de que a mente vai ao encontro do ambiente de forma intensamente ativa, auto direcionada e sem meio termo. Desta forma, nota-se que, os esquemas passam por modificações continuamente e se aprimoram pelas descobertas e por experimentação ativa (FLAVELL et al., 1999).

Com uma voz leve, Vygotsky ${ }^{3}$ destacou um dos focos de sua pesquisa, o estudo dos mecanismos psicológicos mais sofisticados, isto é, "as funções psicológicas superiores, como o

\footnotetext{
${ }^{1}$ Epistemológico: é um sujeito ideal, universal que sintetiza, ao mesmo tempo, as possibilidades de cada pessoa e de todas as pessoas ao mesmo tempo; comparando-se ao sujeito da biologia ou medicina.

${ }^{2}$ Sem referencial, apenas para apoiar a ficção no contexto da escrita.

${ }^{3}$ Sem referencial, apenas para apoiar a ficção no contexto da escrita.
} 
controle do comportamento, a atenção e lembrança voluntária, memorização ativa, pensamento abstrato, raciocínio dedutivo, capacidade de planejamento e etc." (REGO, 1995, p. 25-26).

Explanando, Vygotsky reconhece que, embora discorde da interpretação de Piaget com relação ao pensamento e linguagem aceita "a riqueza do método clínico adotado por Piaget no estudo do processo cognitivo individual e considera a semelhança de interesses no estudo da gênese dos processos psicológicos." (REGO, 1995, p. 33).

Volto às minhas anotações e escrevo: compreende-se que ambos, Piaget e Vygotsky, abordam um mesmo aspecto com nomes diferentes - interiorização pelo primeiro, e internalização pelo segundo. Todavia, além da diferença de nomes existe também uma diferença com relação ao tempo que este fato acontece. Para Piaget, dá-se em meados da infância com o fim do egocentrismo, já para Vygotsky acontece mais cedo, dá-se quando ocorre o diálogo externo que favorece a construção da fala interna, e essa a construção do pensamento.

Com elegância, Piaget agradeceu e acrescentou que "conhecimento implica sistemas de significação." (RAMOZZI-CHIAROTINO, 1998, p. 4). Em meu bloco de notas rapidamente escrevi: a estruturação da teoria piagetiana está baseada na condição de trocas entre o cognitivo e o objeto do conhecimento. De forma esquematizada o processo de adaptação de Piaget está ancorando em quatro conceitos cognitivos que são: esquemas, assimilação, acomodação e equilibração.

Sendo assim, nota-se que, a construção dos esquemas mentais tem início na ação (pensamento, sentimento ou movimento) que é realizada em busca de explicações ou para satisfazer alguma necessidade do sujeito. A ação é que proporciona ao indivíduo troca com o meio e constrói as estruturas mentais, onde, a partir dela se chega à equilibração. Atenta-se para o fato de que é a ação que faz a interação do meio com o organismo, é a partir desta ação que as coisas e fatos, por meio da troca (interação) constroem as estruturas mentais, ou seja, as experiências que levam o indivíduo a atribuição de significados. Assim, o esquema motor (ação) é responsável por proporcionar a significação do objeto para o indivíduo, nesta condição, a organização endógena e exógena, bem como, a razão e experiência se esclarecem, aproximando conhecimento e organismo (RAMOZZI-CHIAROTTINI, 2010; WADWORTH, 1997).

Vygotsky tomou posição em defesa de sua teoria no desenvolvimento da fala e do pensamento e reconhece a importância do egocentrismo do pensamento, mas ainda o critica (1991, p. 14-15) quando Piaget "enfatiza que a fala egocêntrica não cumpre nenhuma função verdadeiramente útil no comportamento da criança, e simplesmente atrofia à medida que a criança se aproxima da idade escolar."

Incorporando um tom mais firme à sua fala, Vygotsky colocou que:

A função primordial da fala, tanto nas crianças quanto nos adultos, é a comunicação, o contato social. A fala mais primitiva da criança é, portanto, essencialmente social. [...] Numa certa idade, a fala social da criança dividese muito nitidamente em fala egocêntrica e fala comunicativa. (1991, p. 17) [...] Toda a concepção do desenvolvimento da fala varia profundamente, de acordo com a interpretação que for dada ao papel da fala egocêntrica. Desse modo, nosso esquema de desenvolvimento - primeiro fala social, depois egocêntrica e, então interior - diverge [...] da sequência de Piaget que parte do pensamento autístico não-verbal à fala socializada e ao pensamento lógico, através do pensamento e da fala egocêntricos. Segundo a nossa concepção o verdadeiro curso de desenvolvimento do pensamento não vai do individual para o socializado, mas do social para o indivíduo. (1991, p. 18). 
Silenciada pelas inquietações, minha mente permanecia agitada com a percepção da construção do conhecimento na mescla dos aspectos internos e sua relação com o com o mundo, além de suas relações às condições psicológicas, sociológicas, filogênicas e ontogênicas.

Morin, por fim, quebrou seu silêncio e pontuou que "o conhecimento do mundo como mundo é necessidade ao mesmo tempo intelectual e vital." (2000, p.35) Com gestos firmes, colocou que, no século XXI, já não resta mais dúvidas que devemos educar "na" e "para" a era planetária com o objetivo de elucidar as características do pensamento complexo. Sendo assim, a educação deve compreender a relação entre antropologia e epistemologia de um ser humano biocultural. Não cabe mais as antropologias culturalistas que negam a ordem biológica do homem, tampouco, os biologismos que observam a cultura determinada pela biologia. Estas condições tendem ao pensamento redutor e simplificador, que no plano da lógica exclui (2003). E que "pretende tornar transparente o laço entre pensamento, linguagem e realidade, que postula a ilusão da normalização absoluta de uma realidade gigantesca, silenciosa e espantosa." (2003, p. 64).

Vygotsky ${ }^{4}$ rompeu meus pensamentos quando colocou que a organização cerebral tem por base sistemas funcionais que atuam de forma articulada e com papel definido dentro de um sistema complexo, e que considera os aspectos filogenéticos e ontogenéticos para o desenvolvimento psicológico humano. Assim, o funcionamento psicológico considera-se como sendo dois momentos um que acontece na relação com o mundo externo (interpsíquica), e outro que se dá internamente (intrapsíquica). Esta transformação de um processo interpessoal para intrapessoal é resultado de um longo caminho no desenvolvimento do indivíduo. São aspectos ligados a internalização de forma culturais e da linguagem, tanto a externa quanto da interna (egocêntrica), e pode ser descrita como processo de internalização, ou seja, reconstrução interna de uma operação externa (PORTILHO, 2011; MOREIRA, 1999; VYGOTSKY, 1991).

Morin, pousando sua xícara de chá sobre a mesa, pondera sobre a necessária reforma do pensamento, todavia, afirma que esta deve ser "paradigmática e, não, programática: é a questão fundamental da educação, já que se refere à nossa aptidão para organizar o conhecimento." (2000, p. 35).

Encerrando o encontro, Piaget acrescentou que o desenvolvimento cognitivo-afetivo apresenta ampliação progressiva, e que esta é contrária ao desenvolvimento orgânico, posto que, este tende ao envelhecimento, todavia, as estruturas mentais tendem a uma mobilidade expansiva no ato de conhecer (NUNES, 2009). Assim, entende-se que a capacidade de construções de operações, que são os sistemas de ações já interiorizados, acabam por se coordenarem entre si, por meio de abstrações reflexionantes que ocorrem nos indivíduos, porém, como decorrência de trocas com o meio.

\section{CONCLUSÕES}

O ambiente escolar sofre os impactos sociais, políticos e econômicos. A aprendizagem ocorre por meio de trocas sociais e de saberes para a construção do conhecimento, e esse é interiorizado e individualizado. Os indivíduos que ali convivem adquirem seus saberes por meio de suas próprias ações cognitivas, e das relações sociais multilaterais que ocorrem entre os professores e alunos. Essas trocas de conhecimentos realizam alterações psicológicas, sociológicas e cognitivas.

Os estudos iniciais de Piaget e Vygotsky possuem uma similaridade no que tange aos aspectos sociais. Piaget não nega a participação do social na construção do conhecimento, contudo, o coloca como o resultado de trocas para a construção das estruturas mentais que conduz à capacidade de conhecer. Para o autor, a condição de equilibração proporciona a construção, reorganização e a ampliação do conhecimento, em virtude das constantes alterações

\footnotetext{
${ }^{4}$ Sem referencial, apenas para apoiar a ficção no contexto da escrita.
} 
das estruturas mentais. Neste aspecto, acaba estabelecendo uma relação com o processo de aprendizagem.

Por outro lado, para Vygotsky a fala é o marco de sua pesquisa e condição para o desenvolvimento cognitivo, desta forma as diferentes classificações e ações das falas egocêntricas, social e comunicativa geram divergências com Piaget. Por conta desta condição, os autores, definem o desenvolvimento de um e de outro como incompletos. De modo particular, percebo similaridades e capacidade de aproximação e de aplicação em conjunto, uma vez que, a construção do conhecimento como reconhece ambos é individual, social e mediado. É fato que Piaget teve mais tempo para concluir suas pesquisas. Acrescente-se a estes célebres autores a capacidade de relacionar ao pensamento de Morin e proporcionar à Educação, aos educadores e educandos uma amplificação quântica na capacidade de compreender, relacionar-se e modificar o pensamento para poder perceber o complexo.

\section{REFERÊNCIAS}

DAFT, R. L. Administração. São Paulo: Cenage Learning, 2010.

DONGO-MONTOYA, A. O. Resposta de Piaget a Vygotsky: convergências e divergências teóricas. Educação e Realidade, Porto Alegre, v. 38, n. 1, p. 271-292, mar. 2013. Disponível em: <http://www.scielo.br/scielo.php?script=sci_arttext\&pid=S2175-

62362013000100015\&lng=en\&nrm=iso>. Acesso em: 12 ago. 2016.

FLAVELL, J. H. et al. Desenvolvimento cognitivo. Porto Alegre: Médicas Sul, 1999.

MOREIRA, M. A. Teorias de aprendizagem. São Paulo: EPU, 1999.

MORIN, E. Os sete saberes necessários à educação do futuro. São Paulo: Cortez; Brasília, DF: UNESCO, 2000.

2002.

. Em busca dos fundamentos perdidos: textos sobre o marxismo. Porto Alegre: Sulina,

NUNES, A. I. B. L.; SILVEIRA, R. N. Psicologia da aprendizagem: processos, teorias e contextos.

Brasília: Líber Livro, 2009.

PIAGET, J.; GUIMARÃES, F. M. Biologia e Conhecimento: ensaio sobre as relações entre as regulações orgânicas e os processos cognoscitivos. Petrópolis: Vozes, 1973a.

PIAGET, J. . Estudos sociológicos. Rio de Janeiro: Forense, 1973b.

PORTILHO, E. M. Como se aprende? Estratégias, estilos e metacognição. Rio de Janeiro: Wak, 2011.

RAMOZZI-CHIAROTTINO, Z. Psicologia e epistemologia genética de Jean Piaget. São Paulo: Pedagógica e Universitária, 1988.

. Piaget segundo seus próprios argumentos. Psicologia USP, São Paulo, v. 21, n. 1, p. 11-30, mar. 2010. Disponível em: <http://www.scielo.br/scielo.php?script=sci_arttext\&pid=S010365642010000100002\&lng=en\&nrm=iso>. Acesso em: 06 fev. 2015. 
REGO, T. C. Vygotsky: uma perspectiva histórico-cultural da educação. Petrópolis, RJ: Vozes, 1995.

GIMENO SACRISTÁN, J. ; PÉREZ GÓMEZ, A. I. Compreender e transformar o ensino. Porto Alegre: Artmed, 1998.

SENGE, P. A quinta disciplina: arte e prática da organização que aprende. Rio de Janeiro: BestSeller, 2013.

SILVEIRA, R. N. Psicologia da aprendizagem: processos, teorias e contextos. Brasília: Liber Livro, 2009.

VYGOTSKY, L. S. Pensamento e linguagem. São Paulo: Martins Fontes, 1991. . et al. Linguagem, desenvolvimento e aprendizagem. São Paulo: Ícone, 2001.

WADSWORTH, B. J. A inteligência e afetividade da criança na teoria de Piaget. São Paulo: Pioneira, 1997. 